\title{
A re-evaluation of goniopholidid crocodylomorph material from Central Asia: Biogeographic and phylogenetic implications
}

Thomas J.D. Halliday, Marco Brandalise de Andrade, Michael J. Benton, and Mikhail B. Efimov Acta Palaeontologica Polonica 60 (2), 2015: 291-312 doi: http://dx.doi.org/10.4202/app.2013.0018

Central Asia is a key area for crocodylomorph evolution, lying midway between the highly documented deposits in Europe and North America, but crocodylomorph fossils from this part of the world are rare. Included among these are specimens collected in the 1970s and 1980s by the Soviet-Mongolian Expeditions in the Jurassic and Cretaceous of Mon-golia, Tajikistan, and Kazakhstan. Three species, "Sunosuchus" shartegensis, Kansajsuchus extensus , and Turanosuchus aralensis are redescribed and subjected to phylogenetic analysis for the first time. "Sunosuchus" shartegensis and Kansajsuchus are relatively derived goniopholidids, and part of a pan-east-Laurasian radiation of goniopholidids from which the European goniopholidids subsequently radiated. No characters can be used to distinguish "Sunosuchus " shartegensis from "S." thailandicus; the two species are therefore synonymized. Turanosuchus aralensis is here considered a nomen dubium. Cladistic analysis suggests that Sunosuchus is polyphyletic, indicating a higher degree of diversification than was previously thought, but also pointing to the need for further systematic revision.

Key words: Reptilia, Crocodylomorpha, Neosuchia, Goniopholididae, phylogeny, Mesozoic, Asia.

Thomas J.D. Halliday [thomas.halliday.11@ucl.ac.uk], School of Earth Sciences, University of Bristol, Bristol, BS8 1RJ; current address:

Department of Earth Sciences, University College London, Gower Street, London, WC1E 6BT; Marco Brandalise de Andrade [marcobranda@yahoo.com.br ], School of Earth Sciences, University of Bristol, Bristol, BS8 1RJ; Departamento de Paleontologia e Estratigrafia, Instituto de Geociências, Universidade Federal do Rio Grande do Sul - UFRGS, Av. Bento Gonçalves 9500, Porto Alegre (RS), 91501-970, C.P. 15001, Brazil; current address: Departamento de Biodiversidade e Ecologia, Faculdade de Biociências, Pontifícia Universidade Católica do Rio Grande do Sul-PUCRS, Avenida Ipiranga, 6681-Prédio 12A / Sala MCT111.01, Porto Alegre (RS), 90619-900, C.P. 1429, Brazil; Michael J. Benton [mike.benton@bristol.ac.uk], School of Earth Sciences, University of Bristol, Bristol, BS8 1RJ; Mikhail B. Efimov [efimov@ @aleo.ru], Paleontological Institute, Russian Academy of Sciences, Profsoyuznaya ul. 123, Moscow 117647, Russia. 
This is an open-access article distributed under the terms of the Creative Commons Attribution License (for details please see creativecommons.org), which permits unrestricted use, distribution, and reproduction in any medium, provided the original author and source are credited.

Fof Full text $(1,249.7 \mathrm{kB})$

FDF Supplementary file $(29.1 \mathrm{kB})$ 